\title{
Intestinal absorption of calcium and magnesium in hepatobiliary disease in infancy
}

\author{
AKIO KOBAYASHI, TAKEKO UTSUNOMIYA, YOSHIRO OHBE, and YOSHIKO NAGASHIMA \\ From the Section of Gastroenterology, Department of Paediatrics, National Children's Hospital, Tokyo
}

\begin{abstract}
Kobayashi, A., Utsunomiya, T., Ohbe, Y., and Nagashima, Y. (1974). Archives of Disease in Childhood, 49, 90. Intestinal absorption of calcium and magnesium in hepatobiliary disease in infancy. The intestinal absorption of calcium and magnesium was measured by metabolic balance studies in 6 normal infants, 13 infants with biliary atresia, 5 infants with successfully repaired biliary atresia, 7 infants with neonatal hepatitis, and 2 infants with choledochal cyst. The absorption of both elements was impaired in these disorders. The malabsorption of these elements was most marked in biliary atresia. In successfully repaired biliary atresia the absorption was increased to the normal levels. In neonatal hepatitis the degree of the malabsorption was variable in individual cases. In choledochal cyst the reduction of the absorption was less marked than in biliary atresia and neonatal hepatitis. In biliary atresia parenteral vitamin $\mathrm{D}$ increased moderately the absorption of both elements, though oral vitamin $\mathrm{D}$ had little effect. In infants with biliary atresia receiving a milk containing medium-chain triglycerides the absorption was moderately raised. There was a clear relation between the absorption of calcium and that of magnesium: the per cent. absorption of magnesium was almost the same as that of calcium in most cases. The serum calcium level determined during the studies was within the normal ranges in hepatobiliary diseases. The serum magnesium level was, however, found to be generally reduced in these conditions. It was greatly reduced in the patients with biliary atresia.
\end{abstract}

Evidence has accumulated that bile salts play an important role in the absorption of calcium and magnesium. (1) Bile salts are essential for the absorption of vitamin D (Schachter, Finkelstein, and Kowarski, 1964), which enhances the intestinal absorption of calcium (Schachter and Rosen, 1959; Sallis and Holdsworth, 1962) and magnesium (Meintzer and Steenbock, 1955; Hanna, 1961; Miller et al., 1965). (2) Bile salts are also important in the process of emulsification and micelle formation in fat absorption (Borgström, 1967); deficiency in the secretion of bile salts would adversely affect fat absorption, and formation of insoluble calcium soaps of unabsorbed fatty acids in the small intestine would reduce calcium absorption (Steggerda and Mitchell, 1951; Kehayoglou et al., 1968b). (3) In addition, bile salts may directly increase calcium absorption (Webling and Holdsworth, 1965).

Received 6 July 1973.
Calcium and magnesium malabsorption is to be expected in chronic biliary obstruction. In animals in which the bile duct was ligated, calcium malabsorption and bone disease has been well documented (Lengemann and Dobbins, 1958; Webling and Holdsworth, 1966; Kehayoglou et al., 1968b). In human adults with prolonged obstructive jaundice and biliary cirrhosis, calcium malabsorption has also been well described (Kehayoglou et al., 1968a; Whelton et al., 1971). In the paediatric age range, however, very little information is available on this subject, and in addition there have been few reports on the intestinal absorption of magnesium in hepatobiliary diseases.

The main diseases which cause obstructive jaundice in infancy are biliary atresia, neonatal 'hepatitis', and choledochal cyst. Of these, biliary atresia produces complete obstruction of bile flow into the gut, such as is rarely encountered in adults. We have studied calcium and magnesium absorption 
in hepatobiliary disease during infancy. In patients with biliary atresia the effects of oral and intramuscular vitamin $\mathrm{D}$, as well as the effects of feeding medium-chain triglycerides, on the absorption of calcium and magnesium were investigated. Furthermore, in some patients with biliary atresia who had been successfully repaired by hepatic portojejunostomy, absorption was studied.

\section{Materials and methods}

The subjects were 13 infants with biliary atresia, 5 infants with biliary atresia who had been successfully repaired by hepatic portojejunostomy and had no jaundice (Kobayashi et al., 1973), 7 infants with neonatal hepatitis, and 2 infants with choledochal cyst. The ages ranged from 1 to 14 months, average 4.8 months.

All patients with biliary atresia had laparotomy and the diagnosis was confirmed. Diagnosis of neonatal hepatitis was on clinical and laboratory grounds, excluding other diseases causing obstructive jaundice during infancy. In practice, the demonstration of bile flow by duodenal intubation, the absence of radiographical signs of choledochal cyst, and a favourable clinical course on follow-up were the chief indicators to a diagnosis of neonatal hepatitis. 2 infants with choledochal cyst had laparotomy and the diagnosis was confirmed.

The infants with biliary atresia were randomly divided into $\mathbf{4}$ groups (in some of the infants 2 or 3 studies were carried out). (A) 10 infants received a proprietary milk, Crown Dia-G* (Morinaga Milk Industry Co., Japan). (B) 4 infants were fed on the same milk as group A and were given orally 2000 to 3000 IU vitamin D daily in divided doses. (C) 5 infants were fed on the same milk as group A and given vitamin D 30,000 IU weekly intramuscularly for 3 to 4 weeks. (D) 4 infants received another proprietary milk, Lipomeal $\dagger$ (New Medical Co., Japan), containing medium-chain triglycerides.

Absorption of calcium and magnesium was measured by determining faecal excretion of these elements. After 5 days of equilibration on the feed, faeces were collected for 3- or 4-day periods. During this time ingested milk was accurately weighed. Faecal calcium and magnesium contents were determined in triplicate. Stools were homogenized in 3- or 4-day periods and 3 small random samples of homogenized materials, about $1 \mathrm{~g}$, were taken and dried at $100^{\circ} \mathrm{C}$, later at $300^{\circ} \mathrm{C}$, and ashed at 600 to $700^{\circ} \mathrm{C}$ for 12 to 16 hours. After the ashings were resolved in $1.0 \mathrm{ml} 3.0 \mathrm{~N} \mathrm{HCl}$ solution they were diluted to $100 \mathrm{ml}$ with distilled water. Calcium was determined

\footnotetext{
*Gas liquid chromatography analysis of Crown Dia-G showed a fatty acid composition of $\mathrm{C}_{4=0} 1 \%, \mathrm{C}_{6=0} 1 \%, \mathrm{C}_{8=0} 3 \%, \mathrm{C}_{10=0}$ $3 \cdot 2 \%, \mathrm{C}_{12}=0 \quad 15 \%, \mathrm{C}_{14=0} 8 \cdot 9 \%, \mathrm{C}_{16=0} 24 \cdot 8 \%, \mathrm{C}_{16=1} 0 \cdot 4 \%$, $\mathrm{C}_{18=0} 4 \cdot 9 \%, \mathrm{C}_{18=1} 24 \cdot 3 \%$, and $\mathrm{C}_{18=2} 13 \cdot 4 \%$. The content of calcium, magnesium, phosphorus, and vitamin $\mathrm{D}$, and calorific value were $294 \mathrm{mg} / 100 \mathrm{~g}, 30 \mathrm{mg}, 270 \mathrm{mg}, 500 \mathrm{IU}$, and $498 \mathrm{cal}$, respectively.

†Analysis of fat in Lipomeal showed the fatty acids to be mainly $\mathrm{C}_{8}=0 \quad 75 \pm 4 \%$ and $\mathrm{C}_{10=0} 25 \pm 4 \%$ with $2 \%$ of $\mathrm{C}_{6=0}$ and $1 \%$ of $\mathrm{C}_{12}=0$. The content of calcium, magnesium, phosphorus, and vitamin $\mathrm{D}$, and calorific value were $533 \mathrm{mg} / 100 \mathrm{~g}, 47 \mathrm{mg}, 500 \mathrm{mg}, 600$ IU, and $500 \mathrm{cal}$, respectively.
}

by a modification of the method of Connerty and Briggs (1966) using the metal complexing dye orthocresolphthalein complexone, and magnesium by the fluorometric method of Schachter (1961) using a spectrofluorometer.

In this study absorption of calcium and magnesium was expressed as

$$
\% \text { Absorption }=\frac{\text { Oral intake }- \text { Faecal excretion }}{\text { Oral intake }} \times 100 .
$$

The results obtained were approximately but not exactly correct, because any absorbed element resecreted into the gut and not subsequently reabsorbed was treated as not absorbed.

Control studies were carried out in 6 infants aged 2 to 7 months (mean 4.5 months), who had been admitted to our department tor acute illness and had been completely cured, in whom absorption was unlikely to have been affected.

During the study, concentrations of calcium and magnesium in serum were determined by the same methods as were used in measuring them in faeces.

\section{Results}

Absorption of calcium and magnesium in hepatobiliary disease in infancy (Fig. 1 and 2). The mean per cent. absorption of calcium in 6 control infants was $63 \%$ with a range of 51 to $70 \%$. That of magnesium in the same group was $59 \%$ with a range of 50 to $68 \%$.

In 10 infants with biliary atresia the absorption of both calcium and magnesium was conspicuously reduced, with the mean value of $34 \%$ (range 20 to $45 \%$ ) and $35 \%$ (range 5 to $47 \%$ ), respectively. The values were significantly lower than the normal. On the other hand, in 5 infants with successfully repaired biliary atresia the absorption of calcium and magnesium was increased to the normal ranges, with the mean value of $59 \%$ (range 55 to 66 ), and $63 \%$ (range 61 to 63 ), respectively.

In neonatal hepatitis the degree of calcium and magnesium malabsorption was variable in individual cases. In choledochal cyst the reduction of the absorption of these elements was less conspicuous than in biliary atresia and neonatal hepatitis.

Effect of vitamin $D$ on calcium and magnesium absorption in biliary atresia (Table I, Fig. 1 and 2). The effect of oral and intramuscular vitamin $\mathrm{D}$ on the intestinal absorption of calcium and magnesium was evaluated in biliary atresia. In 4 infants who were given vitamin D 2000 to 3000 IU daily orally, the mean per cent. absorption of calcium and magnesium was slightly raised compared with the values in 10 patients with biliary atresia receiving no additional vitamin $\mathrm{D}$, but 


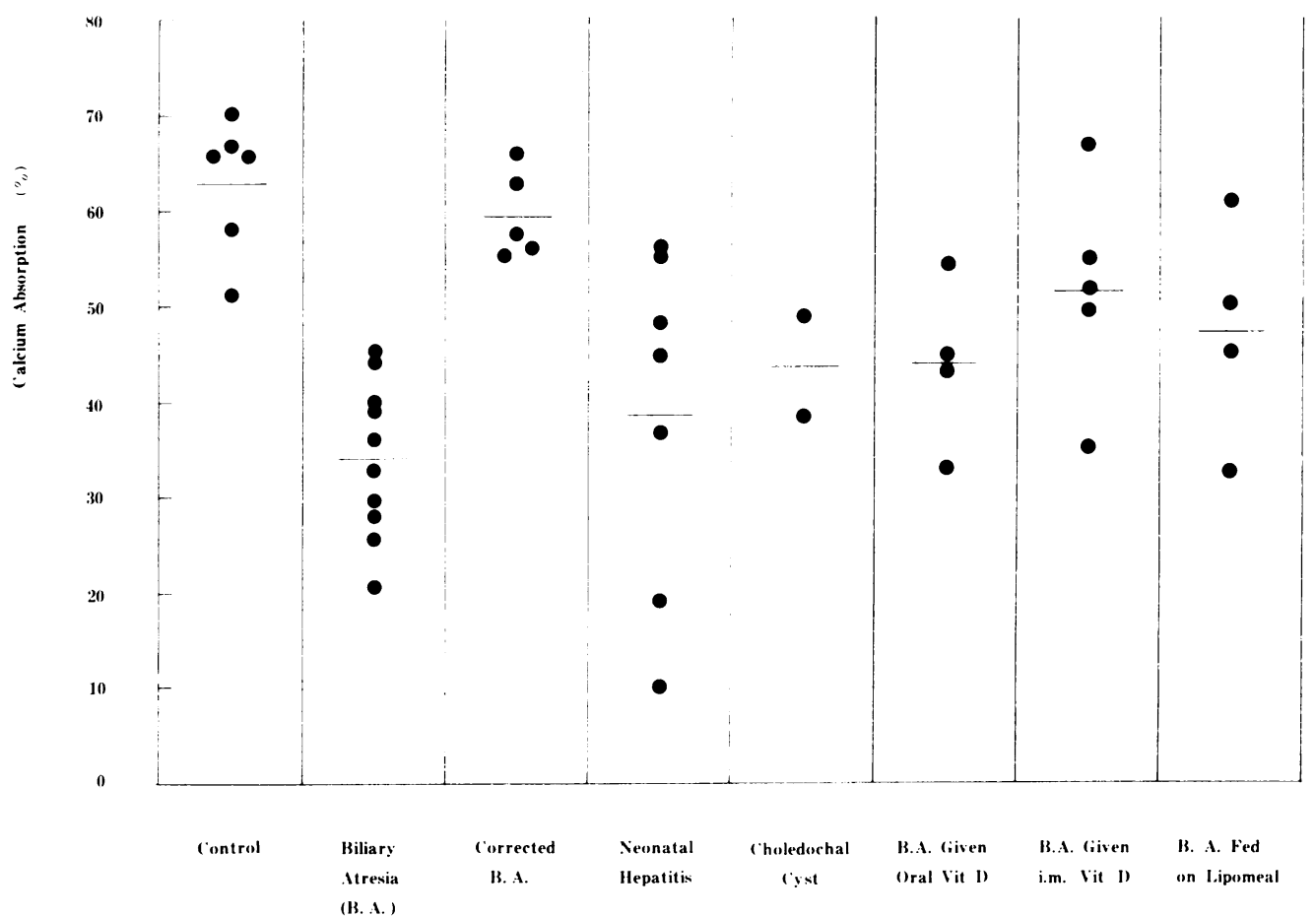

FIG. 1.-Calcium absorption in normal controls and in hepatobiliary disease. Horizontal lines indicate mean value in each group.

was still lower than the normal. In 3 cases the comparison of the absorption before and after the oral vitamin was available. Calcium absorption was increased in only one case (40 to $43 \%$ ) and unchanged ( 44 to $45 \%$ ) or decreased ( 39 to $33 \%$ ) in the other 2. Magnesium absorption was increased in one ( 38 to $48 \%$ ) and unchanged in $2(47$ to $44 \%$ and 42 to $45 \%$ ).

In 5 infants given vitamin D 30,000 IU weekly intramuscularly for 3 to 4 weeks, the absorption of both elements was enhanced. The mean value of calcium absorption was $51.3 \%$, range 34.9 to $66.5 \%$. That of magnesium absorption was $53.5 \%$, range $32 \cdot 9$ to $64 \cdot 1 \%$.
Effect of medium-chain triglycerides on the absorption of calcium and magnesium in biliary atresia (Table II, Fig. 1 and 2). The mean value of calcium and magnesium absorption in 4 infants with biliary atresia who were fed on Lipomeal containing medium-chain triglycerides was $46.9 \%$ (range $32 \cdot 3$ to $60 \cdot 6$ ) and $43.6 \%$ (range $29 \cdot 7$ to $55 \cdot 7)$, respectively. The values were moderately raised compared with the mean values of the infants receiving Crown Dia-G.

Relation between calcium and magnesium absorption (Fig. 3). The relation between calcium and magnesium absorption in all infants is

TABLE I

Effect of oral and intramuscular vitamin $D$ on absorption (\%) of calcium and magnesium in biliary atresia

\begin{tabular}{|c|c|c|c|c|c|}
\hline & \multirow{2}{*}{ No. of cases } & \multicolumn{2}{|c|}{ Calcium } & \multicolumn{2}{|c|}{ Magnesium } \\
\hline & & Mean & Range & Mean & Range \\
\hline $\begin{array}{l}\text { No vitamin D } \\
\text { Oral vitamin D } \\
\text { Intramuscular vitamin D }\end{array}$ & $\begin{array}{r}10 \\
4 \\
5\end{array}$ & $\begin{array}{l}34 \cdot 1 \\
43 \cdot 7 \\
51 \cdot 3\end{array}$ & $\begin{array}{l}20 \cdot 4-45 \cdot 2 \\
32 \cdot 9-54 \cdot 2 \\
34 \cdot 9-66 \cdot 5\end{array}$ & $\begin{array}{l}34 \cdot 7 \\
47 \cdot 4 \\
53 \cdot 5\end{array}$ & $\begin{array}{r}5 \cdot 4-46 \cdot 7 \\
44 \cdot 2-52 \cdot 1 \\
32 \cdot 9-64 \cdot 1\end{array}$ \\
\hline
\end{tabular}




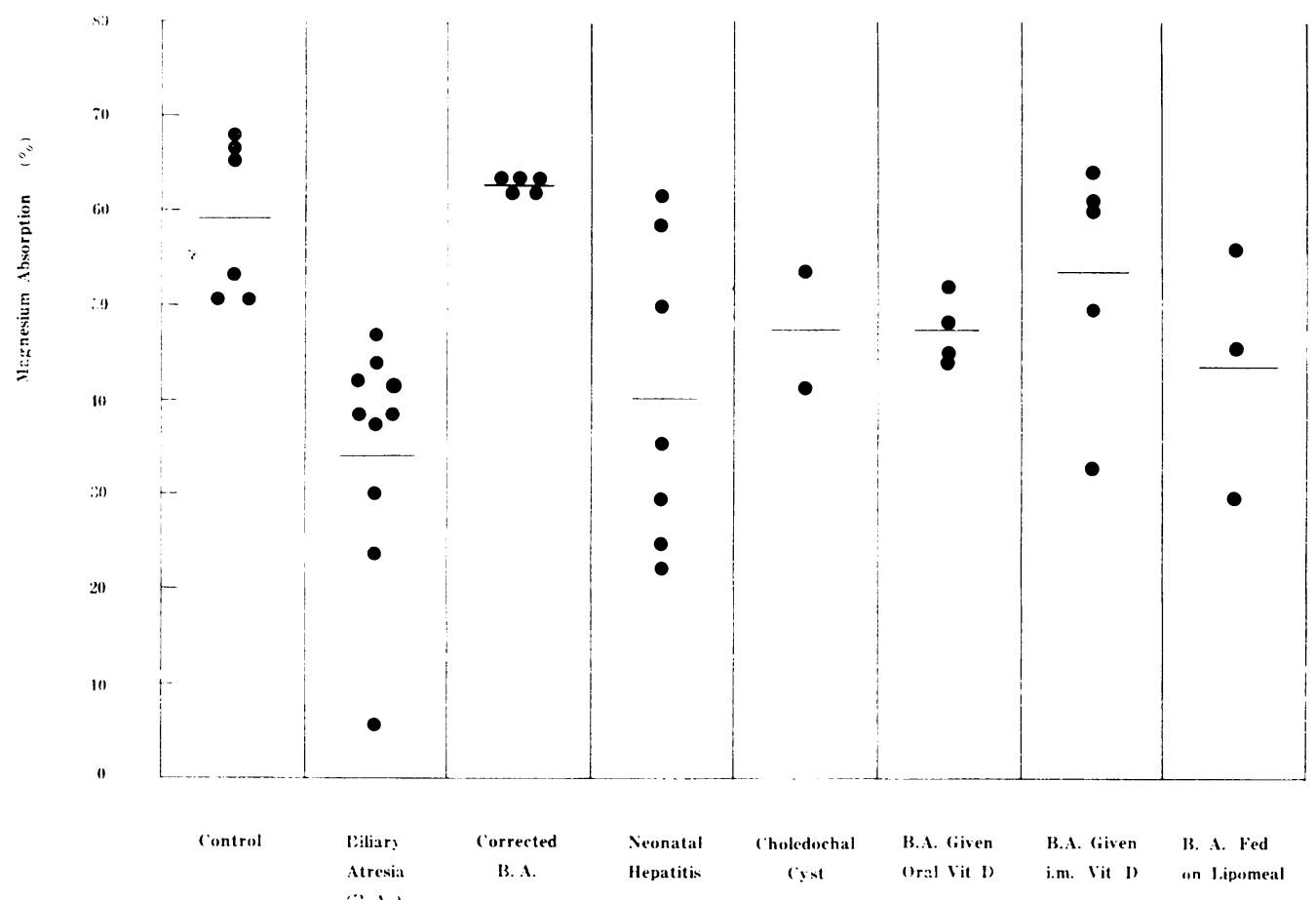

Fig. 2.-Magnesium absorption in normal controls and in hepatobiliary disease. Horizontal lines indicate mean value in each group.

shown in Fig. 3. There is a clear relation between them; the absorption of magnesium was almost the same as that of calcium.

Concentrations of serum calcium and magnesium in hepatobiliary disease (Table III). The serum calcium and magnesium level in each group is summarized in Table III. The serum calcium level was within the normal range in all groups. On the other hand, the serum magnesium level was found to be generally reduced in all groups. It was greatly reduced in the infants with biliary atresia, even when they were given vitamin $\mathrm{D}$ or were fed on a milk containing medium- chain triglycerides, but was reduced to a lesser extent in neonatal hepatitis and choledochal cyst.

\section{Discussion}

Bile, because of its bile salt content, is important for the intestinal absorption of calcium and magnesium, and this has been found both in experimental animals (Lengemann and Dobbins, 1958; Webling and Holdsworth, 1965, 1966; Kehayoglou et al., 1968b) and in human subjects (Kehayoglou et al., 1968a; Whelton et al., 1971). Deficiency or absence of bile flow into the intestines may result in malabsorption of these elements (Kehayoglou et al., 1968a, b; Whelton et al., 1971).

TABLE II

Effect of medium-chain triglycerides on absorption (\%) of calcium and magnesium in biliary atresia

\begin{tabular}{|c|c|c|c|c|c|}
\hline \multirow{2}{*}{ Feed } & \multirow{2}{*}{ No. of cases } & \multicolumn{2}{|c|}{ Calcium } & \multicolumn{2}{|c|}{ Magnesium } \\
\hline & & Mean & Range & Mean & Range \\
\hline $\begin{array}{l}\text { Crown Dia-G } \\
\text { Lipomeal }\end{array}$ & $\begin{array}{r}10 \\
4\end{array}$ & $\begin{array}{l}34 \cdot 1 \\
46 \cdot 9\end{array}$ & $\begin{array}{l}20 \cdot 4-45 \cdot 2 \\
32 \cdot 3-60 \cdot 6\end{array}$ & $\begin{array}{l}34 \cdot 7 \\
43 \cdot 6\end{array}$ & $\begin{array}{r}5 \cdot 4-46 \cdot 7 \\
29 \cdot 7-55 \cdot 7\end{array}$ \\
\hline
\end{tabular}



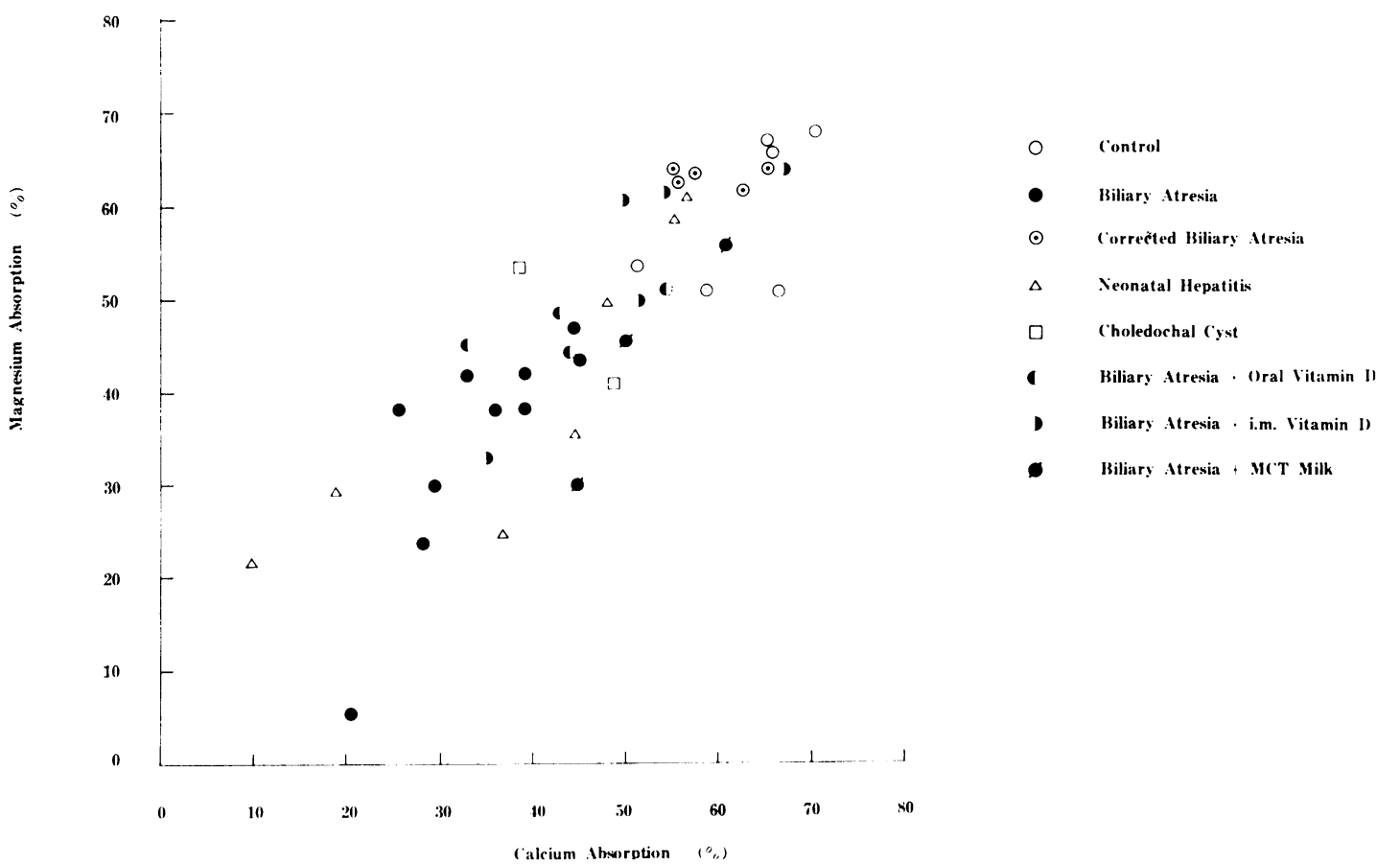

Fig. 3.-Relation of intestinal absorption of magnesium to that of calcium.

In clinical practice, the signs and symptoms attributable to the malabsorption of these elements may be seen in hepatobiliary disease. Bone disease has been described in association with chronic liver disease in adults (Atkinson, Nordin, and Sherlock, 1956; Kehayoglou et al., 1968a). Atkinson et al. (1956) reported 22 patients with obstructive jaundice in 6 of whom a diagnosis of osteomalacia was made. However, there have been con- spicuously few reports on this subject in the paediatric age group (Yu, Walker-Smith, and Burnard, 1971; Kobayashi et al., 1974a).

The present study showed malabsorption of these elements in hepatobiliary disease in infancy. In biliary atresia, in which bile flow into the gut was completely absent, the absorption of both calcium and magnesium was conspicuously reduced. In surgically repaired biliary atresia the absorption was

TABLE III

Serum calcium and magnesium level ( $m E q / l$.$) in hepatobiliary disease$

\begin{tabular}{|c|c|c|c|c|c|}
\hline & \multirow{2}{*}{ No. of cases } & \multicolumn{2}{|c|}{ Calcium } & \multicolumn{2}{|c|}{ Magnesium } \\
\hline & & Mean & Range & Mean & Range \\
\hline $\begin{array}{l}\text { Control } \\
\text { Biliary atresia } \\
\text { Corrected biliary atresia } \\
\text { Neonatal hepatitis } \\
\text { Choledochal cyst } \\
\text { Biliary atresia given oral } \\
\text { vitamin D } \\
\text { Biliary atresia given } \\
\text { intramuscular vitamin D } \\
\text { Biliary atresia fed on milk } \\
\text { containing medium-chain } \\
\text { triglycerides }\end{array}$ & $\begin{array}{r}6 \\
10 \\
5 \\
7 \\
2 \\
4 \\
5 \\
4\end{array}$ & $\begin{array}{l}4 \cdot 6 \\
4 \cdot 8 \\
4 \cdot 6 \\
4 \cdot 9 \\
4 \cdot 8 \\
4 \cdot 8 \\
4 \cdot 5 \\
4 \cdot 8\end{array}$ & $\begin{array}{l}4 \cdot 3-5 \cdot 1 \\
4 \cdot 1-5 \cdot 7 \\
4 \cdot 0-5 \cdot 3 \\
4 \cdot 6-5 \cdot 0 \\
4 \cdot 3-5 \cdot 3 \\
4 \cdot 4-5 \cdot 1 \\
4 \cdot 4-4 \cdot 6 \\
4 \cdot 2-5 \cdot 4\end{array}$ & $\begin{array}{l}1 \cdot 9 \\
1 \cdot 6 \\
1 \cdot 9 \\
1 \cdot 7 \\
1 \cdot 9 \\
1 \cdot 5 \\
1 \cdot 5 \\
1 \cdot 5\end{array}$ & $\begin{array}{l}1 \cdot 8-2 \cdot 0 \\
1 \cdot 3-2 \cdot 0 \\
1 \cdot 8-1 \cdot 9 \\
1 \cdot 6-1 \cdot 8 \\
1 \cdot 8-1 \cdot 9 \\
1 \cdot 2-1 \cdot 6 \\
1 \cdot 3-1 \cdot 6 \\
1 \cdot 4-1 \cdot 7\end{array}$ \\
\hline
\end{tabular}


increased to the normal ranges. In neonatal hepatitis and choledochal cyst the degree of calcium and magnesium malabsorption was less conspicuous than in biliary atresia. It seems from our results that malabsorption of calcium and magnesium noted in hepatobiliary disease may be partly explained by deficiency or absence of bile salts.

The role of bile is indirect in the intestinal absorption of calcium and magnesium in that it is necessary for the absorption of vitamin $\mathrm{D}$ (Schachter et al., 1964), which enhances the absorption of both elements. Heymann (1937) reported that the vitamin disappeared from the serum of dogs when the bile duct was ligated. Furthermore, vitamin D that is absorbed from the gastrointestinal tract via the lymphatics and is transported from there to the liver in the chylomicron of the plasma may be hydroxylated in the liver to a more potent metabolite, 25-hydroxycholecalciferol (25-HCC) (Lund and DeLuca, 1966; Ponchon, Kennan, and DeLuca, 1969), which is thought to be converted to more active forms, 1,25 - or 21,25 -dihydroxycholecalciferol $(1,25-$ or $21,25-\mathrm{DHCC})$, in the kidneys (Fraser and Kodicek, 1970). Since the initial step of transformation of vitamin $\mathrm{D}$ to its active form may take place in the liver, there may be a failure to metabolize the vitamin adequately and there is some evidence that this may occur in hepatic cirrhosis (Ponchon and DeLuca, 1969). This mechanism may participate in causing malabsorption of calcium and magnesium in hepatobiliary disease in infancy.

The present study showed that in biliary atresia oral vitamin D had little, if any, effect on the absorption of these elements. On the other hand, the vitamin moderately heightened the absorption when given intramuscularly. It is reasonable to ccnclude from our results that vitamin $D$ is necessary for efficient absorption of these elements, and that vitamin D may not be absorbed from the gut in the absence of bile.

Although it has been well known that vitamin D influences the absorption of calcium, there is little information about the effect of the vitamin on the absorption of magnesium. Meintzer and Steenbock (1955) reported that vitamin D caused a slight, but significant, increase in the intestinal absorption of magnesium in the rat. Hanna (1961) and Miller et al. (1965) confirmed this. Our own observations accord better with those of Meintzer and Steenbock (1955), and show that vitamin D enhances the absorption of magnesium to the same extent as that of calcium.

There have been a few reports on the effect of fat on calcium absorption in man, though very little information is available on its effect on magnesium absorption (Tantibhedhyangkul and Hashim, 1971). Steggerda and Mitchell (1951) reported that in steatorrhoea calcium absorption might be reduced as a result of the formation of insoluble calcium soaps in the intestinal lumen, and this was confirmed by Kehayoglou et al. (1968a), Southgate et al. (1969), and Agnew and Holdsworth (1971). In general, it is likely that calcium absorption may be depressed by triglycerides containing fatty acids with longchain lengths and a high degree of saturation (Tadayyon and Lutwak, 1969). On the other hand, it appears that medium-chain triglycerides stimulate calcium absorption (Agnew and Holdsworth, 1971), even if there are no bile salts in the intestinal lumen (Kehayoglou et al., 1968b). Our results showed that in the infants with biliary atresia the absorption of both elements was increased when they were fed on a milk containing medium-chain triglycerides.

Concentrations of magnesium in serum were reduced in hepatobiliary disease. These findings were formerly reported by Kobayashi and Shiraki (1967) who found that magnesium level was greatly reduced in biliary atresia, but to a lesser extent in other hepatic disorders including neonatal hepatitis and choledochal cyst. On the other hand, reduction of serum calcium level was rarely encountered in these conditions. If present, it was not as severe as that of serum magnesium. The maintenance of serum calcium within the normal ranges might be attributable to secondary hyperparathyroidism observed in chronic obstructive jaundice (Losper, Lemaire, and Lesobre, 1939). The infants with biliary atresia showed a reduced value of per cent. tubular reabsorption of phosphate (\% TRP) (Kobayashi, Utsunomiya, and Ohbe, 1974b). Serum magnesium level, on the other hand, may be influenced by parathyroid hormone (Barnes, Krane, and Cope, 1957; Potts and Roberts, 1958) as well as by aldosterone (Kobayashi and Igarashi, 1968). The secretion of aldosterone is increased in cirrhosis of the liver (Coppage et al., 1962) and it may produce the reduction of serum magnesium level through increased urinary excretion of the ion (Horton and Biglieri, 1962; Cohen, McNamara, and Finberg, 1970).

We are indebted to many members of the staff of the National Children's Hospital of Tokyo; and we acknowledge the important contributions to this study of the nursing staff of the $2-\mathrm{W}$ and $4-\mathrm{W}$ wards and the hospital nutritionists.

\section{REFERENCES}

Agnew, J. E., and Holdsworth, C. D. (1971). The effect of fat on calcium absorption from a mixed meal in normal subjects, patients with malabsorptive disease, and patients with a partial gastrectomy. Gut, 12, 973. 
Atkinson, M., Nordin, B. E. C., and Sherlock, S. (1956). Malabsorption and bone disease in prolonged obstructive jaundice. Quarterly fournal of Medicine, 25, 299.

Barnes, B. A., Krane, S. M., and Cope, O. (1957). Magnesium studies in relation to hyperparathyroidism. Fournal of Clinical Endocrinology and Metabolism, 17, 1407.

Borgström, B. (1967). Absorption of fats. Proceedings of the Nutrition Society, 26, 34.

Cohen, M. I., McNamara, H., and Finberg, L. (1970). Serum magnesium in children with cirrhosis. Fournal of Pediatrics, 76, 453.

Connerty, H. V., and Briggs, A. R. (1966). Determination of serum calcium by means of orthocresolphthalein complexone. American fournal of Clinical Pathology, 45, 290.

Coppage, W. S., Jr., Island, D. P., Cooner, A. E., and Liddle, G. W. (1962). The metabolism of aldosterone in normal subjects and in patients with hepatic cirrhosis. Fournal of Clinical Investigation, 41, 1672.

Fraser, D. R., and Kodicek, E. (1970). Unique biosynthesis by kidney of a biologically active vitamin $\mathrm{D}$ metabolite. Nature (London), 228, 764.

Hanna, S. (1961). Influence of large doses of vitamin D on magnesium metabolism in rats. Metabclism, 10, 735 .

Heymann, W. (1937). Metabolism and mode of action of vitamin D. IV. Importance of bile in the absorption and excretion of vitamin D. Fournal of Biological Chemistry, 122, 249.

Horton, R., and Biglieri, E. G. (1962). Effect of aldosterone on the metabolism of magnesium. Fournal of Clinical Endocrinology and Metabolism, 22, 1187.

Kehayoglou, A. K., Holdsworth, C. D., Agnew, J. E., Whelton, M. J., and Sherlock, S. (1968a). Bone disease and calcium absorption in primary biliary cirrhosis. With special reference to vitamin-D therapy. Lancet, 1,715 .

Kehayoglou, A. K., Williams, H. S., Whimster, W. F., and Holdsworth, C. D. (1968b). Calcium absorption in the normal, bile-duct ligated, and cirrhotic rat, with observations on the effect if long- and medium-chain triglycerides. Gut, 9, 597.

Kobayashi, A., and Igarashi, Y. (1968). Serum magnesium level in the salt-losing type of congenital adrenal hyperplasia. Archives of Disease in Childhood, 43, 223.

Kobayashi, A., and Shiraki, K. (1967). Serum magnesium level in infants and children with hepatic diseases. Archives of Disease in Childhood, 42, 615.

Kobayashi, A., Utsunomiya, T., Kawai, S., and Ohbe, Y. (1974a). Bone disease in infants and children with hepatobiliary diseases. (In preparation).

Kobayashi, A., Utsunomiya, T., and Ohbe, Y. (1974b). Hyperparathyroidism in hepatobiliary disease. (In preparation).

Kobayashi, A., Utsunomiya, T., Ohbe, Y., and Shimizu, K. (1973). Ascending cholangitis after successful surgical repair of biliary atresia. Archives of Disease in Childhood, 48, 697.

Lengemann, F. W., and Dobbins, J. W. (1958). The role of bile in calcium absorption. Fournal of Nutrition, 66, 45.

Loeper, M., Lemaire, A., and Lesobre, R. (1939). Spondylomalacie dans la cirrhose biliaire. Archives des Maladies de l'Appareil Digestif et des Maladies de la Nutrition, 29, 577.

Lund, J., and DeLuca, H. F. (1966). Biologically acive metabolite of vitamin $\mathrm{D}_{3}$ from bone, liver, and blood serum. Fournal of Lipid Research, 7, 739.
Meintzer, R. B., and Steenbock, H. (1955). Vitamin D and magnesium absorption. Fournal of Nutrition, 56, 285.

Miller, E. R., Ullrey, D. E., Zutaut, C. L., Hoefer, J. A., and Luecke, R. W. (1965). Mineral balance studies with the baby pig: effects of dietary vitamin $\mathrm{D}_{2}$ level upon calcium, phosphorus and magnesium balance. Fournal of Nutrition, 85, 255.

Ponchon, G., and DeLuca, H. F. (1969). The role of the liver in the metabolism of vitamin D. Fournal of Clinical Investigation, 48, 1273.

Ponchon, G., Kennan, A. L., and DeLuca, H. F. (1969). 'Activation' of vitamin D by the liver. Fournal of Clirical Investigation, 48, 2032.

Potts, J. T., Jr., and Roberts, B. (1958). Clinical significance of magnesium deficiency and its relation to parathyroid disease. American Fournal of the Medical Sciences, 235, 206.

Sallis, J. D., and Holdsworth, E. S. (1962). Influence of vitamin D on calcium absorption in the chick. American fournal of Physiology, 203, 497.

Schachter, D. (1961). Fluorometric estimation of magnesium with 8-hydroxy-5-quinolinesulfonate. Fournal of Laboratory and Clinical Medicine, 58, 495.

Schachter, D., Finkelstein, J. D., and Kowarski, S. (1964). Metabolism of vitamin D. I. Preparation of radioactive vitamin $\mathrm{D}$ and its intestinal absorption in the rat. Fournal of Clinical Investigation, 43, 787.

Schachter, D., and Rosen, S. M. (1959). Active transport of $\mathrm{Ca}^{45}$ by the small intestine and its dependence on vitamin D. American Fournal of Physiology, 196, 357.

Southgate, D. A. T., Widdowson, E. M., Smits, B. J., Cooke, W. T., Walker, C. H. M., and Mathers, N. P. (1969). Absorption and excretion of calcium and fat by young infants. Lancet, 1, 487.

Steggerda, F. R., and Mitchell, H. H. (1951). The calcium balance of adult human subjects on high- and low-fat (butter) diets. Fourna! of Nutrition, 45, 201.

Tadayyon, B., and Lutwak, L. (1969). Effects of dietary triolein, tripalmitin, and L-phenylalanine on calcium absorption in the rat. Proceedings of the Society for Experimental Biology and Medicine, 130, 978.

Tantibhedhyangkul, P., and Hashim, S. A. (1971). Enhanced calcium and magnesium absorption in premature infants by feeding formulas containing medium chain triglyceride (MCT). Pediatric Research, 5, 387.

Webling, D. D'A., and Holdsworth, E. S. (1965). The effect of bile bile acids and detergents on calcium absorption in the chick., Biochemical fournal, 97, 408.

Webling, D. D'A., and Holdsworth, E. S. (1966). Bile salts and calcium absorption. Biochemical fournal, 100, 652.

Whelton, M. J., Kehayoglou, A. K., Agnew, J. E., Turnberg, L. A., and Sherlock, S. (1971). ${ }^{47}$ Calcium absorption in parenchymatous and biliary liver disease. Gut, 12, 978.

Yu, J. S., Walker-Smith, J. A., and Burnard, E. D. (1971). Rickets: a common complication of neonatal hepatitis. Medical fournal of Australia, 1, 790.

Correspondence to Dr. A. Kobayashi, Department of Paediatrics, National Children's Hospital, Taishido 3-35-31, Setagaya-ku, Tokyo, Japan. 